\title{
Evaluation of the Community Cataract Surgical Services of a University Teaching Hospital Using Cataract Surgical Coverage in Nigeria
}

\author{
Olokoba $\mathbf{L}^{1}$, Mahmoud $\mathrm{O}^{2}$, Adepoju $\mathrm{F}^{2}$, Olokoba $\mathrm{A}^{3}$, Durowade $\mathrm{K}^{4}$
}

\begin{abstract}
BACKGROUND: Cataract is the leading cause of blindness in the world. An efficient and effective cataract surgical service is necessary to reduce the backlog of cataract blindness in the community. This study aims to determine the cataract surgical coverage among individuals aged 50 years and above residing in Esie and Arandun communities. This will serve as a measure of the impact of the cataract intervention programme provided by the University of Ilorin Teaching Hospital, Nigeria.

METHODS: The study was a population-based, cross sectional survey conducted from November to December, 2013. Cataract surgical services are provided by the University of Ilorin Teaching Hospital, Nigeria, at Esie and Arandun communities as out-reach centres. Seven hundred and fifty-five individuals aged 50 years and above residing in these communities had basic ocular examination done.

RESULT: Out of the 765 subjects registered, 755(98.7\%) were examined. Out of these, $38.4 \%$ were males and $61.6 \%$ were females. The prevalence of bilateral cataract blindness was 1.6\%. The Cataract Surgical Coverage (eyes) at visual acuity $<3 / 60$ for males and females were $52.3 \%$ and $51.2 \%$ respectively $(X 2=19.30, p=0.001)$, while the Cataract Surgical Coverage (person) at visual acuity less $<3 / 60$ for males and females were $80.6 \%$ and $68.4 \%$ respectively $(X 2=2.10, p=0.147)$.

CONCLUSION: The Cataract Surgical Coverage was high with a correspondingly low prevalence of cataract blindness in these communities. The availability of cataract surgical services via out-reach programmes bridges the gap between eye care-givers and the community.
\end{abstract}

KEYWORDS: Cataract Surgical Coverage, Cataract Surgical Services, Community, Evaluation

DOI: http://dx.doi.org/10.4314/ejhs.v26i2.4

\section{INTRODUCTION}

Cataract is the leading cause of blindness in the world (1). Data from the Nigerian blindness survey estimated an increase by $43.0 \%$ in the number of people with severe visual impairment and blindness from cataract by the year 2020 if the current incidence of severe visual impairment and blindness due to cataract and cataract surgical coverage remain essentially unchanged (2). Thus, there is a need for effective and efficient cataract surgical services to achieve the goals of vision 2020. Periodic evaluation of the cataract surgical services is necessary to readjust plans for greater effectiveness, to improve services and to measure achievements of the programme (3).

Cataract surgical services are evaluated using several indicators such as measuring the cataract surgical rate/million population/per year, and measuring the cataract surgical coverage. These two assess the quantity of the services. Others include sight restoration rate, success rate (these measure the quality of the surgical services), cataract operations/surgeon/year (measures resource utilization) etc (3).

\footnotetext{
${ }^{1}$ Department of Ophthalmology, General Hospital, Ilorin, Nigeria

${ }^{2}$ Department of Ophthalmology, University of Ilorin Teaching Hospital, Ilorin, Nigeria

${ }^{3}$ Department of Medicine, University of Ilorin Teaching Hospital, Ilorin, Nigeria

${ }^{4}$ Department of Epidemology, University of Ilorin Teaching Hospital, Ilorin, Nigeria

Corresponding Author: Olokoba Abdulfatai, Email: drabolokoba@gmail.com
} 
Traditionally, cataract intervention programme is evaluated by the cataract surgical rate (4), but it does not indicate the extent to which the problem of cataract blindness has been reduced in the community because data to determine the cataract surgical rate are derived from the hospital records not the community (3). Cataract Surgical Coverage (CSC), however, is a community-based parameter that compares the proportion of people who have received surgery (aphakic and pseudophakic) to the total, that is those who still need surgery and those who have had surgery (operable cataract + aphakic + pseudophakic) in a certain area. It indicates the extent to which cataract surgical services have covered the needs of the community. It measures the effectiveness of the cataract intervention programme in providing surgical services (4).

Cataract surgical coverage (CSC) is calculated for eyes and for people, at visual acuity $<3 / 60,<6 / 60$ and $<6 / 18$. CSC (person) indicates the extent to which the need for cataract surgical services has been met. It measures the success of vision 2020 initiative to eliminate cataract blindness. While CSC (eyes) relates more to the total surgical workload of the ophthalmologist i.e the proportion of eyes with operable cataract that have had surgery in the community at a given point in time (4). The Nigeria blindness survey put CSC (eyes) to be $22.8 \%$ and CSC (person) to be $37.2 \%$ at visual acuity of $<3 / 60$ in individuals aged 40 years and above in Nigeria (5). CSC (person) was the highest in the South-west, Nigeria $(46.1 \%)$ and the lowest in the South-south Nigeria $(21.6 \%)$. In the North-central zone of the country, CSC (eyes) was $30.7 \%$, and CSC (person) was $41.5 \%$.

Surveys carried out at various parts of Nigeria reported similarly low CSC for eyes and person. In Northern Nigeria, Rabiu reported cataract intervention (surgery and couching) coverage of $22.1 \%$ for people aged 40 years and above living in a rural community of Katsina State. CSC (person) was $4.0 \%$ while couching coverage was $18.0 \%$ (6). Kolawole et al reported a CSC (person) of $12.1 \%$ and couching coverage at $11.8 \%$ at visual acuity $<3 / 60$ in people aged 50 years and above in Egbedore, South-west Nigeria (7). Higher CSC compared to what was reported by the Nigerian national blindness survey was reported in Rwanda and Kenya $(8,9)$.
This study aims to evaluate the cataract surgical services provided by the University of Ilorin Teaching Hospital, Ilorin, Nigeria, in two rural communities where it provides communitybased cataract surgical services by calculating the cataract surgical coverage for these communities. This is to measure the extent to which the cataract surgical services provided have covered the needs of the community, and also to provide baseline data that will be useful for the planning of subsequent eye care programmes at the community level.

\section{MATERIALS AND METHODS}

The study was a population-based, cross sectional survey of people aged 50 years and above residing in Esie and Arandun communities in Irepodun local government area (LGA) of Kwara State, Nigeria. Ethical approval was obtained from the Ethics and Research Committee of UITH, Ilorin. Informed consent was obtained from the people enrolled.

Sample Size Calculation: The sample size was determined using the statcalc menu of Epi info software, version 6, November 1993. The following parameters were used:

- The total population of people aged 50 years and above living in Esie and Arandun communities $=1,737$. This was based on the estimates that $9.5 \%$ of adults in the communities are aged 50 years and above (10). The total population of Esie and Arandun communities was 18,283. Thus $9.5 \%$ of 18,283 was 1,737 .

- Prevalence of cataract blindness $=3.6 \%{ }^{6}$

- Worst acceptable prevalence $=2.6 \%$.

- Precision $=1 \%$

- $95 \%$ confidence interval

- The calculated sample size was thus $\mathbf{7 5 4}$.

Data Collection: The research team consisted of an ophthalmologist, an ophthalmic nurse, a trained research assistant, and a community guide. All individuals aged 50 years and above within a household and residing in the two communities were recruited. At each house, the process of data collection was in three stages: the first stage involved registration of all eligible subjects at each house. A research assistant (the community health extension worker) obtained information such as name, age, sex, occupation, etc and 
recorded them on the general information section of the survey form. The second stage involved visual acuity measurement by the ophthalmic nurse. The enlisted persons' visual acuity was tested using Snellen's tumbling 'E' chart at 6 meters $(m)$ in daylight. Direct sun rays on the chart or the face of the person were avoided. Persons had to correctly identify $50 \%$ or more (2 out of 4 or 2 out of 3 ) of the optotypes presented before they were given a score for the optotype visual level. Persons with visual acuity $<6 / 18$ in either eye had their vision re-tested in that eye with pinhole to obtain the best corrected vision. Any eye that could not see the $6 / 60$ optotype at $6 \mathrm{~m}$ was re-tested at $3 \mathrm{~m}$, then at $1 \mathrm{~m}$. If still unable to see at that distance, the eye was assessed as light perception or no light perception. Visual acuity was also measured with the person's spectacles if the individual had spectacle correction. At the third stage, the researcher carried out the ocular examination on all the subjects and filled other sections of the survey record form. The subjects were taken to a darkened part of the house for ocular examination. The anterior segment examination was with a pen torch, binocular magnifying loupe and direct ophthalmoscope. The lens status was assessed by pen torch and distant direct ophthalmoscopy at $25 \mathrm{~cm}$ in $\operatorname{dim}$ illumination without dilatation of the pupil. The lens was assessed to be normal if there was a clear or minimal dark shading of the red reflex on distant direct ophthalmoscopy. Obvious lens opacity was present when the lens appeared grey or white when examined with pen torch with an obvious dark shading of the red reflex observed on distant direct ophthalmoscopy. Aphakia was present when there was no lens in the central pupil, and pseudophakia was present when an intraocular lens (IOL) was seen in the eye. The presence of a posterior capsule opacification was noted. The inability to view the lens owing to the presence of dense corneal opacity, phthisis bulbi, or absent globe was also noted.

Posterior segment examination was carried out on all subjects in a darkened part of the house with a direct ophthalmoscope. Examining the eye in dim illumination allows for physiological mydriasis of the pupil and thus better view of the fundus.
Intraocular pressure was measured with hand held Perkins tonometer in people with suspicious discs (cup/disc ratio $\geq 0.5$ ), and in those with visual acuity $<6 / 60$. Thereafter, the pupils of subjects with visual acuity $<6 / 60$ were dilated with mydriacyl ${ }^{\mathrm{R}}$ and $2.5 \%$ phenylephrine to determine the cause of poor vision in them.

The principal cause of visual impairment (presenting visual acuity less than 6/18) was determined in each eye as well in the individual. When two principal disorders co-exist in an eye, the most amenable to treatment or easily prevented was adjudged to be the principal cause of visual impairment in the eye in accordance with the World Health Organisation (WHO) convention (11). In determining the cause of visual impairment for a person, the principal disorder in the better eye was selected. Those with diagnosis of cataract were asked the reasons why they had not done cataract surgery. Those with signs of past cataract surgery were asked details about the cataract surgery.

If a house was locked up, or when an eligible person was not around to be examined, a repeat visit was made to the house later on the same day, and again the next day. If contact could not be established after the two visits, the person was categorised as non-responding.

All the subjects adjudged to need further evaluation were referred to the eye clinic of Esie comprehensive centre. The recorded data were entered, cleaned and analysed with Epi info software, version 6.

\section{RESULTS}

A total of 765 people were registered, out of whom 755 people were examined giving an overall coverage of $98.7 \%$. The age range in the survey population was $50-99$ years. The mean age was 64.0. The majority of the people were females $465(61.6 \%)$ with a male to female ratio of $1: 1.6$ [Table 1].

Farming was the predominant occupation, $319(42.3 \%)$ people. The prevalence of bilateral cataract blindness among the survey population was $1.6 \%$ (CI 0.7-1.8). The prevalence of bilateral cataract blindness was higher in males compared to females $(\mathrm{X} 2=0.69, \mathrm{p}=0.551)$. The prevalence of monocular blindness from cataract in the survey population was 7.7\% (CI 5.8-9.5) [Table 2]. 
Table 1: Age and Gender distribution of survey population

\begin{tabular}{llllllc}
\hline & Males & \multicolumn{2}{c}{ Females } & \multicolumn{2}{c}{ Total } \\
Age group & No & $\%$ & No & $\%$ & No & $\%$ \\
\hline $50-59$ & 67 & 8.9 & 115 & 15.2 & 182 & 24.1 \\
$60-69$ & 115 & 15.2 & 207 & 27.4 & 322 & 42.6 \\
$70-79$ & 66 & 8.7 & 72 & 9.5 & 138 & 18.3 \\
$\geq 80$ & 42 & 5.6 & 71 & 9.4 & 113 & 15.0 \\
\hline All ages & 290 & 38.4 & 465 & 61.6 & 755 & 100.0 \\
\hline
\end{tabular}

Table 2: Prevalence of cataract with $\mathrm{VA}<3 / 60, \mathrm{VA}<6 / 60$ and $\mathrm{VA}<6 / 18$

\begin{tabular}{|c|c|c|c|c|c|c|}
\hline \multirow[t]{2}{*}{ Level of visual acuity } & \multicolumn{2}{|c|}{ Males } & \multicolumn{2}{|c|}{ Females } & \multicolumn{2}{|c|}{ Total } \\
\hline & $\mathrm{n}$ & $\%$ & $\mathrm{n}$ & $\%$ & $\mathrm{n}$ & $\%(\mathrm{CI})$ \\
\hline \multicolumn{7}{|c|}{ Cataract blindness with $\mathrm{VA}<3 / 60$ with best correction or pinhole } \\
\hline Bilateral cataract blind & 6 & 2.1 & 6 & 1.3 & 12 & $1.6(0.7-1.8)$ \\
\hline Unilateral cataract blind & 29 & 10.0 & 29 & 6.2 & 58 & $7.7(5.8-9.5)$ \\
\hline Cataract blind eyes & 41 & 7.1 & 41 & 4.4 & 82 & $5.4(4.0-6.7)$ \\
\hline \multicolumn{7}{|c|}{ Cataract with $\mathrm{VA}<6 / 60$ with best correction or pinhole } \\
\hline Bilateral Cataract & 13 & 4.5 & 13 & 2.8 & 26 & $3.4(0.1-1.4)$ \\
\hline Cataract eyes & 62 & 10.7 & 62 & 6.7 & 124 & $8.2(1.3-4.3)$ \\
\hline \multicolumn{7}{|c|}{ Cataract with VA $<6 / 18$ with best correction or pin hole } \\
\hline Bilateral cataract & 20 & 6.9 & 30 & 6.5 & 50 & $6.6(0.8-2.9)$ \\
\hline Cataract eyes & 83 & 14.3 & 110 & 11.8 & 193 & $12.8(2.9-6.3)$ \\
\hline
\end{tabular}

\section{Cataract surgical coverage (CSC)}

CSC (person) in subjects with $\mathrm{VA}<3 / 60$ was $74.5 \%$. Coverage was higher in males than females at visual acuities less than $3 / 60,6 / 60$ and 6/18. $(\mathrm{X} 2=2.10, \mathrm{p}=0.147) \mathrm{CSC}$ in eyes was $51.8 \%$ at VA $<3 / 60$. Males had higher cataract surgical coverage compared to females at visual acuities less than 3/60, 6/60 and 6/18. (X2=19.30, $\mathrm{p}=0.001)$.[Table 3]

Table 3: Cataract Surgical Coverage among the survey population

\begin{tabular}{lllllll}
\hline $\begin{array}{l}\text { Visual } \\
\text { acuity }\end{array}$ & \multicolumn{2}{c}{ Cataract Surgical Coverage (eyes) } & \multicolumn{3}{l}{ Cataract Surgical Coverage (person) } \\
\hline & Male (\%) & Female (\%) & Total (\%) & Male (\%) & Female (\%) & Total (\%) \\
VA $<3 / 60$ & 52.3 & 51.2 & 51.8 & 80.6 & 68.4 & 74.5 \\
VA $<6 / 60$ & 42.1 & 41.0 & 41.6 & 65.8 & 58.1 & 62.0 \\
VA<6/18 & 35.2 & 28.1 & 31.7 & 56.5 & 44.4 & 50.5 \\
\hline \multicolumn{2}{l}{ VA= Visual Acuity } & & & &
\end{tabular}


Barriers to Cataract Surgery: The commonest barrier to uptake of cataract surgery reported by people blinded from cataract was inability to afford surgery $(52.0 \%)$. This was followed by the belief that cataract surgery was not necessary as blindness was due to old age (19.0\%) [Figure 1].

\section{Barriers to uptake of cataract surgery}

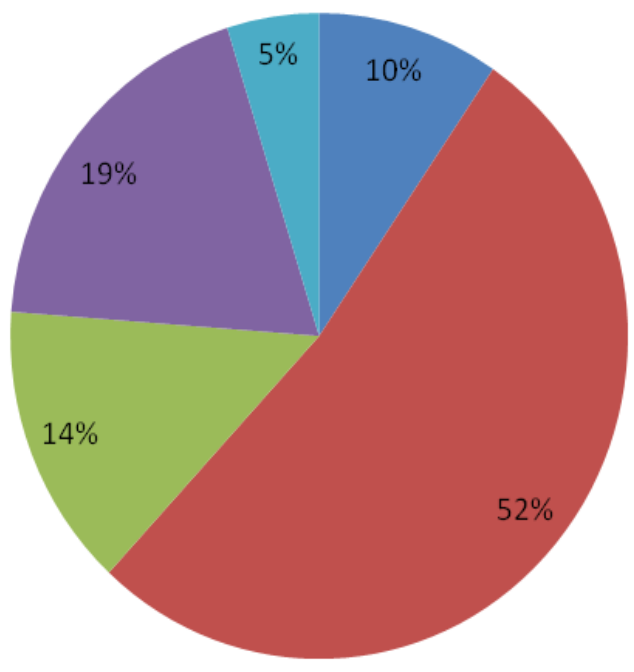

- Unaware of treatment

- Cost of surgery

- Lack of escort

- Old age: no need

n fear of losing sight

Figure 1: Barriers to cataract surgery

\section{DISCUSSION}

This study limited the subjects recruited to the age group of 50 years and older as age related cataract blindness mainly affects people of 50 years and older. The coverage of $98.7 \%$ in this survey was high. This was made possible by the immense support given by the community leaders who encouraged the people to participate. Also, the field work was carried out in the afternoon and evening which allowed those who went to farm, market and civil services to have returned home to participate in the survey.

The prevalence of bilateral cataract blindness $(1.6 \%)$ from this study is slightly lower than that of the national prevalence of $1.8 \%$ (2). The low prevalence of cataract blindness may be attributed to the presence of the health centre located within the vicinity that offers regular and subsidised cataract surgical services. Also, regular monthly screening for cataract and other blinding eye diseases in the communities within the local government area is carried out by the outreach team of UITH, Ilorin. This raises the awareness of the people on cataract blindness and the need to have surgery. It also helped to clear whatever doubt they may have about cataract surgery. A low prevalence of cataract blindness $(0.83 \%)$ was reported by Oluleye in Akinyele LGA, South-west Nigeria, in people aged 50 years and above (12). The low prevalence of cataract blindness was also attributed to the presence of a health facility in the community that was linked to a tertiary eye centre.

High prevalences of cataract blindness had been reported in studies from different parts of Nigeria. The prevalence of bilateral cataract 
blindness among people aged 50 years and above ranged between $2.1 \%$ and $3.8 \%$ in Northern Nigeria $(6,13,14)$ and $4.1 \%$ in the Niger Delta region of Nigeria (15). Kolawole et al reported a prevalence of cataract blindness of $2.0 \%$ in Osun State, South-west Nigeria (7).

At visual acuity of $<3 / 60$, the CSC for person was high $(74.5 \%)$ in the survey area. The high coverage corresponded with the low prevalence of cataract blindness reported in this study. The CSC of $74.5 \%$ is higher than the $41.5 \%$ reported by the national blindness survey for the North-central zone of Nigeria. The value is also much higher than the values reported in several parts of the country. For example, CSC (person) at visual acuity $<3 / 60$ was $22.1 \%$ in Katsina state (6), and $28.9 \%$ in Kebbi state (14). It was $4.1 \%$ in Ughelli, South-south Nigeria (15) and $12.1 \%$ in Osun State, South-west Nigeria (7). This difference is probably due to better availability and subsidised cataract services in the study area. The CSC was, however, comparable to those of other countries in sub-Sahara Africa where community-based cataract intervention programmes are available: in Kenya with CSC (person) of 78.0\% (9), in South west province of Cameroon with CSC (person) of $80.0 \%$ (16), and in the Kilimanjaro region of Tanzania with CSC (person) of $69.8 \%$ (17).

Cataract surgical coverage was higher in males compared to females (80.6\% vs. 68.4\%). Higher CSCs for males compared with females have been reported in other surveys carried out in Nigeria, and other developing countries $(6,7,9,13)$. The gender difference is attributable to better access to surgical services by the men. The rural women have limited control over the household finances and the cost of surgery is often prohibitive to them (13). The CSC at visual acuity $<6 / 60$ was also high suggesting that people were operated before they were 'blind' from cataract which implies availability of services and good uptake of cataract surgical services in the area.

Despite the high coverage per person, there is still a significant backlog of operable cataract in the area with about half of the eyes blinded from cataract yet to receive surgery; CSC (eyes) was $51.8 \%$ at visual acuity $<3 / 60$ and about $60.0 \%$ of eyes with operable cataract yet to have surgery. (CSC eyes at VA < 6/60 was $41.6 \%$ ).

The cost of surgery was found to be the most common barrier to the uptake of cataract surgery with $52.0 \%$ of those blind from cataract citing inability to afford the cost of operation as the reason why surgery had not been done. This is in spite of the fact that the cost of cataract operation at our outreach centre $(7,500$ Naira, which is equivalent to \$50) is highly subsidized and one of the cheapest in the country. The above quoted price is the direct cost of surgery. By adding the indirect cost of transportation, feeding, medications, loss of revenue for the accompanying relative(s) etc, the summation of the direct and indirect cost may be excessively beyond the ability of the poor subsistent farmers who participated in this study except they are assisted by their relations. Cost as a barrier to uptake of cataract services has been widely reported by previous studies in Nigeria $(6,13,18)$. A positive correlation was reported between cost reduction and uptake of cataract services by Gyasi et al in Ghana (19). A reduction in the cost of surgery and provision of transport expenses translated into a significant increase in cataract surgical acceptance (19). While it may not be possible to further reduce the fees for cataract operations, the introduction of the National Health Insurance Scheme to cover rural communities may overcome this major barrier. It is surprising that some of the respondents, despite being bilaterally blind, did not see cataract surgery as a necessity. These findings are consistent with others which show that the presence and guarantee of eye care services do not necessarily translate into service uptake. While they are not seeing cataract surgery as a necessity although poor vision is attributed to the patients' adaptation and the general cultural acceptance of blindness as an inevitable part of the ageing process. Continued health education by the community health workers on the safety of cataract surgery and emphasing that everyone has the right to a sighted life irrespective of their age is very useful in overcoming this barrier. Elderly pseudophakics in the community can be used as motivators.

The strength of this study lies in its high coverage of the study population. Although the limitation of this study is that the survey was only carried out in the communities where UITH, Ilorin has its outreach centre.

In conclusion, cataract surgical coverage is high in the survey population with a correspondingly low prevalence of cataract 
blindness. The availability of cataract surgical services via out-reach programmes bridges the gap between eye care givers and the community. This, among other factors is the key to reducing the backlog of cataract blindness in our communities. However, there is a need to further increase the CSC through further cost curtailment methods as a backlog of operable cataract still exists within the area.

\section{ACKNOWLEDGEMENTS}

I appreciate the good people of Esie and Arandun communities in North-central Nigeria for their cooperation and hospitality. I also acknowledge the contributions of members of my research team.

\section{REFERENCES}

1. Pascolini D, Mariotti SP. Global estimates of visual impairment: 2010. $\mathrm{Br} J$ Ophthalmol 2012;96(5):614.

2. Abdull MM, Sivasubramaniam S, Murthy GV, Gilbert C, Abubakar T, Ezelum C, et al. Causes of blindness and visual impairment in Nigeria: the Nigeria national blindness and visual impairment survey. Invest Ophthalmol Vis Sci 2009;50(9):4114-20.

3. Gilbert DC. planning and evaluating cataract services. In: Kyari F, editor. Community Eye Health Module. 2 ed. National Eye Centre, Kaduna: West Afr Coll Surg 2005:49-55.

4. Limburg H, Foster A. Cataract Surgical Coverage: An indicator to measure the impact of cataract intervention programmes. Community Eye Health J 1998;11(25):3-6.

5. Kyari F, Gudlavalleti MV, Sivsubramaniam S, Gilbert CE, Abdull MM, Entekume G, et al. Prevalence of blindness and visual impairment in Nigeria: the National Blindness and Visual Impairment Study. Invest Ophthalmol Vis Sci 2009;50(5):2033-9.

6. Rabiu MM. Cataract blindness and barriers to uptake of cataract surgery in a rural community of northern Nigeria. $\mathrm{Br} \quad J$ Ophthalmol 2001;85(7):776-80.

7. Kolawole OU, Ashaye AO, Mahmoud AO, Adeoti CO. Cataract blindness in Osun state, Nigeria: results of a survey. Middle East Afr J Ophthalmol 2012;19(4):364-71.
8. Mathenge W, Nkurikiye J, Limburg H, Kuper $\mathrm{H}$. Rapid assessment of avoidable blindness in Western Rwanda: blindness in a postconflict setting. PLoS Med 2007;4(7):e217.

9. Mathenge W, Kuper H, Limburg H, Polack S, Onyango O, Nyaga G, et al. Rapid assessment of avoidable blindness in Nakuru district, Kenya. Ophthalmol 2007;114(3):599-605.

10. National Population Commission. Final results of 1991 population census of Nigeria for Kwara State.

11. Limburg H. Estimating Cataract Surgical Services in National Programme; computer soft ware: World Health Organization (WHO) Prevention of Blindness and Deafness, Geneva, 2001.

12. Oluleye TS. Cataract blindness and barriers to cataract surgical intervention in three rural communities of Oyo State, Nigeria. Niger $J$ Med 2004;13(2):156-60.

13. Odugbo OP, Mpyet CD, Chiroma MR, Aboje AO. Cataract blindness, surgical coverage, outcome, and barriers to uptake of cataract services in Plateau State, Nigeria. Middle East Afr J Ophthalmol 2012;19(3):282-8.

14. Rabiu M, Muhammed N. Rapid Assessment of Cataract Surgical sevices in Birnin Kebbi Local Government Area of Kebbi State, Nigeria. Ophthalmic Epidemiol 2008;15(6):359-65.

15. Patric-Ferrife G, Ashaye AO, Osuntokun OO. Rapid Assessment of Cataract Blindness among Ughelli Clan in urban/rural district of Delta State,Nigeria. Ann Afr Med 2005;4(2):52-57.

16. Oye JE, Kuper H, Dineen B, Befidi-Mengue $R$, Foster A. Prevalence and causes of blindness and visual impairment in Muyuka: a rural health district in South West Province, Cameroon. Br J Ophthalmol 2006;90(5):53842.

17. Habiyakire $\mathrm{C}$, Kabona $\mathrm{G}$, Courtright $\mathrm{P}$, Lewallen S. Rapid assessment of avoidable blindness and cataract surgical services in kilimanjaro region, Tanzania. Ophthalmic Epidemiol 2010;17(2):90-4.

18. Omolase CO, Omolase BO, Fadamiro CO, Adido J, Adepoju FG. Barriers to Uptake Of Orthodox Eye Care In a Rural Nigerian Community. Trop J Health Sci 2007;14(2):2325. 
19. Gyasi M, Amoaku W, Asamany D. Barriers to cataract surgical uptake in the upper East region of ghana. Ghana Med J 2007;41(4):16770. 